\title{
BMJ open Condom use during commercial sex among clients of Hijra sex workers in Karachi, Pakistan (cross-sectional study)
}

\author{
Anees ur Rehman Siddiqui, ${ }^{1,2}$ Han-Zhu Qian, ${ }^{1,3}$ Arshad Altaf, ${ }^{1,2}$ Holly Cassell, ${ }^{1}$ \\ Sharaf Ali Shah, ${ }^{2,4}$ Sten H Vermund ${ }^{1,5}$
}

To cite: Siddiqui AuR, Qian $\mathrm{H}-\mathrm{Z}$, Altaf $\mathrm{A}$, et al. Condom use during commercial sex among clients of Hijra sex workers in Karachi, Pakistan (cross-sectional study). BMJ Open 2011;1:e000154 doi:10.1136/bmjopen-2011000154

- Prepublication history for this paper is available online. To view these files please visit the journal online (http:// bmjopen.bmj.com).

Received 6 May 2011 Accepted 22 August 2011

This final article is available for use under the terms of the Creative Commons Attribution Non-Commercial 2.0 Licence; see http://bmjopen.bmj.com

For numbered affiliations see end of article.

Correspondence to Dr Anees Siddiqui; asiddiqui09@hotmail.com

\section{ABSTRACT}

Objective: To describe the prevalence and predictors of condom use and sexual risk in the male clients of Hijra sex workers (HSWs) in Karachi, Pakistan.

Design: Cross-sectional study.

Setting: Karachi, Pakistan.

Participants: Clients of HSWs were recruited with assistance from HSWs and a non-governmental organisation (NGO) focused on men who have sex with men (MSM) during October-November 2010.

Measurements: The interviewer administered the questionnaire to each participant to solicit information on demographics, HIV/AIDS knowledge/attitudes and sexual risk behaviours/practices, including condom use in the last sexual act with the HSW.

Results: Of the 203 participants, $42.4 \%$ reported that they used condoms during their last sexual act with HSW, $40 \%$ were married, $18 \%$ had ever used drugs or alcohol, and $52 \%$ reported also engaging with female sex workers in the last month. Casual HSW clients were more likely to use condoms than regular clients (adjusted OR (AOR), 2.50; 95\% Cl 1.34 to 4.65), as were persons with a higher education level (AOR 5.8; $95 \% \mathrm{Cl} 1.6$ to 20.3). Drug/alcohol users and non-users were equally likely to use condoms (AOR $1.11 ; 95 \% \mathrm{Cl}$ 0.51 to 2.24).

Conclusion: Clients of HSWs in Pakistan are at risk of acquiring HIV/STI infections. Concerted efforts are needed to increase condom use in this key bridge population to curtail the spread of HIV in the general population.

\section{INTRODUCTION}

Since the diagnosis of the first HIV case in Pakistan in 1987, more than 4000 HIV/AIDS cases have been registered with the National AIDS Control Programme (2010). ${ }^{1}$ The Joint United Nations Programme on HIV and AIDS estimated the number of people living with HIV/AIDS in Pakistan to be between 79000 and 120000 in $2009 .^{2}$ In the period from 2003 to 2008, a high HIV prevalence was found among different high-risk populations, including injection-drug users (IDUs) in Sarghoda City in northern Pakistan (53\%)

\section{ARTICLE SUMMARY}

\section{Article focus}

- To determine the prevalence of condom use in regular and casual clients of Hijra sex workers.

Key messages

- It is feasible to access hard-to-reach populations.

- The intervention programme should also focus on clients.

Strengths and limitations of this study

- This is the first study of its kind.

- The study involved no HIV testing.

- The study gave an incentive to clients and Hijra sex workers for participating in the study.

and in Karachi City in the south (23\%), Hijra sex workers (HSWs, male transgender or transvestite sex workers) in Larkana (28\%) and Karachi (4\%), as well as non-Hijra men who have sex with men (MSM) in Larkana $(0.5 \%)$ and Karachi $(3 \%){ }^{3}$ Based on sentinel surveillance data, the principal risks of HIV transmission in Pakistan include all major routes: heterosexual and homosexual contacts, IDU and transfusion of unscreened blood or blood products. Transmission of HIV from mother to infant is described but is not as common because men dominate the current Pakistani epidemic (10:1 male:female ratio in reported cases).

While IDU transmission has dominated Pakistani incidence since $2003,{ }^{4}$ unprotected commercial sexual contacts, particularly commercial homosexual contacts, have become an increasing concern. ${ }^{5}$ Fully $97 \%$ of Pakistan's population is Muslim, and religious and social norms strongly forbid extramarital sex. The introduction of Islamic 'Hudood' laws prohibiting and punishing promiscuity by the military government in 1979 and subsequent crackdown campaigns led to the closure of many brothels and red-light areas. This drove commercial sex activities underground. The historic 
brothel-based pattern of commercial sex activities has been replaced by a diverse and dispersed pattern where sex workers (women, men and transgenders) sell sex in public spaces such as parks or streets, and even at their homes. Home from where female sex worker operates is called "Kothikhana" and home from where HSW operates is called "Dera". According to recent estimates, only about $2-3 \%$ of HSW and female sex worker (FSWs) operate from brothels or red-light areas. ${ }^{6}$

Despite the context of a socially conservative Pakistani society, risky sexual behaviours are still prevalent. A 2007 national study of 2400 men in the general population showed that $30 \%$ had non-marital sex in their lifetimes; these included $41 \%$ of men reporting sex with FSWs, $14 \%$ with MSWs including HSWs and 65\% with girlfriends ( $>100 \%$ due to multiple answers). ${ }^{7}$ A study among 690 migrant workers found that $13 \%$ reported non-marital sex in the past 12 months; $62 \%$ of these were sex with FSWs. ${ }^{8}$ Such estimates from interview-based surveys are likely underestimating true behavioural risk rates owing to social response bias, that is, "telling the interviewer what he wants to hear.'

Unprotected anal sex is estimated to pose a higher risk per coital act of transmitting HIV than vaginal sex. ${ }^{9} 10$ Studies from Thailand and elsewhere suggest that clients of sexual workers may serve as a bridge for transmitting HIV from high-risk populations to the general population. ${ }^{11}{ }^{12}$ Many male clients of HSWs in Pakistan are married or have girlfriends, and they may also have FSW contacts. Although there are a few studies of HIV prevalence and risk behaviours among FSW and male sex workers in Pakistan, ${ }^{3}{ }^{5}{ }^{13-15}$ there is no published research among clients of sex workers; and in South Asia as a whole, we have been unable to find a single peerreviewed publication of research among HSW clients. We evaluated the prevalence and predictors of condom use and sexual-risk behaviours linked to sexually transmitted infection (STI) risk in clients of HSWs (ie, commercial sex contacts) in Karachi, Pakistan.

\section{METHODS}

\section{Study design and participant recruitment}

We conducted the study in October-November 2010 in Karachi, Pakistan's largest city, port and commercial hub. The study was given ethical approval by the Institutional Review Board of Vanderbilt University, USA and Bridge Consultants Foundation, Pakistan. HSW clients were recruited with the assistance of a local non-governmental organisation (NGO) in Karachi that provides counselling and disease-prevention services for MSM and Hijra populations. We organised two workshops in order to prepare for the study. In the first recruitment workshop, the study was explained to $>100 \mathrm{HSWs}$ attendees; we invited 50 willing HSWs to recruit their clients for participation in the study. In the second training workshop, the 50 volunteer HSWs, street outreach workers from the MSM-friendly NGO and the local research team received training on the study protocol, ethical issues and consent procedures, participant recruitment, communication skills and questionnaire administration, followed by mock interviews with 'clients.'

The 50 volunteer HSWs helped us recruit their clients by discussing the study, and contacting the study outreach workers at the partner NGO for interested clients by sending a text message or by making a phone call. Study outreach workers then approached the willing clients at the sex venues or other venues of convenience and transported them to the NGO office, where oral consent for participation and questionnaire interviews were completed. The whole process of transporting and interviewing took an average of $90 \mathrm{~min}$. Each participant who completed the interview received a compensation of 500 Pakistan Rupees (US\$5.90) for their time. The 50 HSWs who assisted with participant recruitment received reimbursement for their phone calls plus 1000 Pakistan Rupees (US\$11.80, one time only) for compensation for their time (figure 1).

\section{Measurements}

The questionnaire included enquiries on the following themes: (1) socio-demographics; (2) HIV/AIDS knowledge and sexual-risk behaviours; and (3) condom use in the last commercial sex act with a HSW. We did not assess HIV or STI infection among study participants in this study, owing to our desire to have maximum participation for the interviews. We are preparing a follow-up study to extend our work, including the provision of STI screening.

\section{Case definitions}

Client of HSW

A client of HSW was defined as any male 18 years old and above and who had paid sex with the HSW in last 6 months.

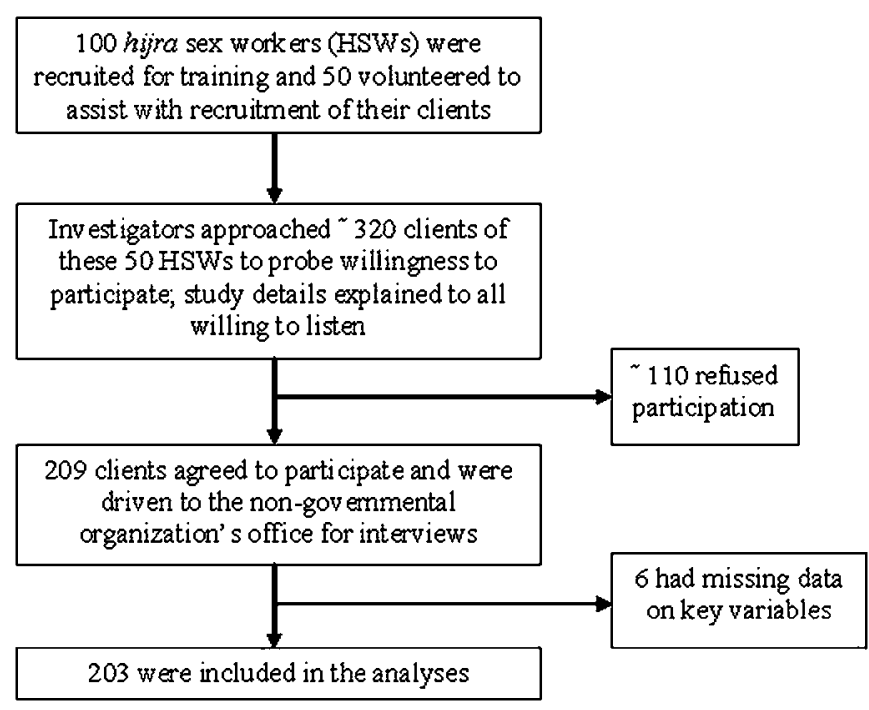

Figure 1 Participant recruitment. 
Regular client

A regular client was defined as any client of HSW who had paid sex at least three times with the same HSW in last 30 days.

\section{Casual client}

A casual client was defined as any client of HSW who had paid sex less than three times with the same HSW in last 30 days.

\section{Statistical analysis}

Questionnaire data were double-entered and compared using EpiInfo V.3.5.1. After data cleaning, the database was imported into STATA using Stat/Transfer and analysed using Stata/IC V.11.1.

We tested two hypotheses: (1) condom use is more common in sex with casual HSW clients than with regular HSW clients; and (2) illicit drug/alcohol-using clients are less likely to use condoms compared with nondrug/alcohol-using clients. The primary outcome was condom use in the last commercial sexual encounter with the HSW. The primary predictor variable for hypothesis 1 was the nature of clients (regular versus casual clients), and the primary predictor variable for hypothesis 2 was use of illicit drugs or alcohol during sex. The potential confounding factors included sociodemographic and HIV-related knowledge and behavioural factors. Frequency was calculated for categorical variables, and the mean and IQR were calculated for continuous variables. A $\chi^{2}$ test and Wilcoxon rank-sum test were performed to compare condom use between regular versus casual clients in bivariable analyses, and multivariable logistic regression analyses were then performed to adjust for any potential confounding factors. For logistic models, we included variables relevant to our original hypotheses as well as independent variables whose associations with condom use during the last HSW sex were $\mathrm{p}<0.05$ in bivariable comparisons.

\section{RESULTS}

We estimate that $60 \%$ of approached HSW clients agreed to participate, but we do not have precise confirmation, as this is from HSW reports. Of the $50 \mathrm{HSWs}$ who helped with recruitment, $41(82 \%)$ actually referred willing clients to the study.

\section{Socio-demographics of study participants}

A total of 209 HSW clients completed the survey. Six had missing data on key variables, and 203 participants were included in the final analyses. The median age was 29 years (IQR: 24-35); 15\% were illiterate, $63 \%$ had some primary- or middle-school education, and $22 \%$ had college or higher-level education. Never-married and migrant status was common; $60 \%$ were never married, and $73 \%$ were migrants workers from other parts of the Pakistan (out of Karachi). The median HIV/AIDS knowledge score was 9 (IQR: 8-11; range: 0-14); $53 \%$ reported sex with FSWs in the last month (table 1).

\section{Commercial sex with HSWs}

Forty-four per cent of clients were regular clients of HSW, while 56\% were casual clients. Of the 203 study subjects, $79 \%$ of participants said they made their last commercial sex transaction with the HSWs directly, while the remainder did so via intermediates-for example, pimps, gatekeepers or gurus. The amount paid for the last sex ranged from 50 to 1500 rupees (US $\$ 0.60-17.60)$. Over half $(53 \%)$ of these sexual encounters took place at HSW homes. Nearly one in five (19\%) clients said they used drugs or alcohol during the last commercial sex. Of the clients who used lubricants during their last HSW sexual encounter $(n=186), 20.5 \%$ used oil, $9.1 \%$ used a water-based lubricant, and $69.3 \%$ used saliva (table 1). Forty-two per cent of participants $(\mathrm{n}=86)$ reported using condoms in the last sex act with HSWs (table 1).

Table 1 Socio-demographics and HIV-related knowledge and behaviours of 203 clients of Hijra sex workers in Karachi, Pakistan

\begin{tabular}{|c|c|}
\hline Variable & Median (IQR) \\
\hline Age, years & $29(24-35)$ \\
\hline \multirow[t]{2}{*}{ HIV/AIDS knowledge score } & $9(8-11)$ \\
\hline & Frequency (\%) \\
\hline \multicolumn{2}{|l|}{ Formal education } \\
\hline None & $30(14.8)$ \\
\hline Grades 1-8 & $129(63.5)$ \\
\hline Grades 9 or above & $44(21.7)$ \\
\hline \multicolumn{2}{|l|}{ Marital status } \\
\hline Never married & $122(60.1)$ \\
\hline Ever married & 81 (39.9) \\
\hline \multicolumn{2}{|l|}{ Local resident of Karachi } \\
\hline Yes & $54(26.6)$ \\
\hline No & $149(73.4)$ \\
\hline \multicolumn{2}{|l|}{ Who made the last sex deal } \\
\hline Self & $161(79.3)$ \\
\hline Others & $42(20.7)$ \\
\hline \multicolumn{2}{|l|}{ Condom used in last sex } \\
\hline Yes & $86(42.4)$ \\
\hline No & $117(57.6)$ \\
\hline \multicolumn{2}{|l|}{ Type of lubricant used } \\
\hline Saliva & $129(63.5)$ \\
\hline Water-based lube & $17(8.4)$ \\
\hline Oil & $40(19.7)$ \\
\hline No lubricant use & $17(8.4)$ \\
\hline \multicolumn{2}{|l|}{ Drugs/alcohol used in last sex } \\
\hline Yes & 38 (18.7) \\
\hline No & 165 (81.3) \\
\hline \multicolumn{2}{|l|}{ Venue of last sex } \\
\hline Hijra sex worker home & $107(52.7)$ \\
\hline Other & $96(47.3)$ \\
\hline \multicolumn{2}{|c|}{$\begin{array}{l}\text { Had sex with female sex worker } \\
\text { In past } 30 \text { days }\end{array}$} \\
\hline Yes & $114(56.1)$ \\
\hline No & 89 (43.9) \\
\hline \multicolumn{2}{|l|}{ Type of hijra sex worker } \\
\hline Regular & $84(41.4)$ \\
\hline Casual & 119 (58.6) \\
\hline
\end{tabular}


Predictors of condom use in the last commercial sexual encounter

In bivariate analyses, the relationship of condom use with age, education level, marital status, HIV/AIDS knowledge score and type of client was statistically significant at a significance level of $\mathrm{p}<0.05$, while the relationship with drug/alcohol use was not. All of these factors were included in the final multivariate variables as per prior hypothesis testing. Adjusting for other potential confounders, casual HSW clients were more likely to use condoms than regular clients (AOR 2.50; $95 \%$ CI 1.34 to 4.65 ), while drug/alcohol users were equally likely to use condoms as non-users (AOR 1.11; $95 \%$ CI 0.51 to 2.24$)$. Those with a higher education level were more likely to use condoms (AOR 5.8, 95\% CI, 1.6 to 20.3) (table 2).

\section{DISCUSSION}

Hijra is a gender concept for biological males in South Asia who regard themselves as female. ${ }^{16}$ They often make a living by performing dances at weddings and childbirth ceremonies. HSWs are transvestites/transsexuals who undertake sexual activity with a man in return for money or other financial benefits. Compared with FSWs in Pakistan, HSWs are more easily approached by their male clients owing to the popularity of social activities among males and greater tolerance towards extramarital sex with males than with females. Therefore, HSWs are quite common in large cities. The national surveillance data suggest there are about 35000 HSWs across the country and around 10000 in Karachi City. ${ }^{17}$ The number of HSW clients is likely to be many times higher than the number of HSWs, but to our knowledge this has never been estimated.

Our study is the first of its kind to study the male clients of HSWs. We found that casual clients of HSWs were more likely to use condoms but that drug/alcohol use did not predict condom use. Regular clients may feel a level of confidence in the HSW not shared by the casual client. This result is similar to findings in FSW studies around the world. ${ }^{18}{ }^{19}$ Familiarity with a sex worker can give a false sense of security, of course, as both HSWs and their clients may have risky sex with other sexual partners.

In addition to low condom use (42\% as self-reported), other characteristics of HSW clients also suggest that this population is at high risk of acquiring and transmitting HIV. Over half $(52 \%)$ of participants reported visiting FSWs in the past month, and $40 \%$ were currently married, suggesting their bridge potential into a general population via FSW, spouses, girlfriends and/or children via female partners. There were many misunderstandings regarding HIV/AIDS; the average score of HIV/ AIDS knowledge was nine out of a total 14 points. Intervention programmes are needed urgently to increase knowledge and awareness among HSW clients and HSWs themselves, and to reduce unprotected anal sex.

Our study's strengths include the success we had in recruitment in this first ever study of HSW client knowledge, attitudes, practices and behaviours. An estimated three-fifths of men approached were recruited into the study.

Study limitations included self-reporting of data during the interview; social response-related reporting bias may indicate that our estimates of high-risk behaviours are underestimates, and protective behaviours are overestimates, as with condom use. The study also included an incentive for participants including sex workers and their clients. This could lead to bias and collusion; however, in this sociocultural setting, it is not possible to approach the client directly. Our resources

Table 2 Predictors for condom use during the last commercial sexual encounter among clients of Hijra sex workers in Karachi, Pakistan

\begin{tabular}{|c|c|c|c|c|c|c|}
\hline Variable & $\begin{array}{l}\text { No of } \\
\text { participants }\end{array}$ & $\begin{array}{l}\text { Condom use } \\
(\mathrm{n}, \%)\end{array}$ & OR (95\% Cl) & p Value & $\begin{array}{l}\text { Adjusted OR } \\
(95 \% \mathrm{Cl})\end{array}$ & p Value \\
\hline $\begin{array}{l}\text { Age (every } 10 \\
\text { years increase) }\end{array}$ & 203 & $117(57.6)$ & 0.63 (0.43 to 0.92$)$ & 0.02 & 0.75 (0.46 to 1.23$)$ & 0.3 \\
\hline \multicolumn{7}{|l|}{ Education } \\
\hline None & 30 & $26(86.7)$ & 1.0 & \multirow[t]{3}{*}{0.001} & 0 & \multirow[t]{3}{*}{0.02} \\
\hline Grades 1-8 & 129 & $71(55.1)$ & $5.3(1.75$ to 16.1$)$ & & $4.3(1.27$ to 12.8$)$ & \\
\hline Grades 9-16 & 44 & $20(45.5)$ & $7.8(2.32$ to 26.1$)$ & & $5.8(1.60$ to 20.3$)$ & \\
\hline \multicolumn{7}{|l|}{ Marital status } \\
\hline Never married & 122 & $64(52.5)$ & 1.0 & \multirow[t]{2}{*}{0.02} & 0 & \multirow[t]{2}{*}{0.3} \\
\hline Ever married & 81 & $53(65.4)$ & $0.49(0.28$ to 0.87$)$ & & $0.68(0.32$ to 1.43$)$ & \\
\hline $\begin{array}{l}\text { HIV/AIDS knowledge score } \\
\text { (every three-point increase) }\end{array}$ & 203 & $117(57.6)$ & 1.14 (1.02 to 2.19$)$ & 0.04 & $1.34(0.88$ to 2.00$)$ & 0.2 \\
\hline \multicolumn{7}{|c|}{ Use of alcohol/drugs in last sex } \\
\hline No & 165 & $96(58.2)$ & 1.0 & \multirow[t]{2}{*}{0.7} & 0 & \multirow[t]{2}{*}{0.8} \\
\hline Yes & 38 & $21(55.3)$ & $1.13(0.55$ to 2.29$)$ & & $1.11(0.51$ to 2.24$)$ & \\
\hline \multicolumn{7}{|c|}{ Type of hijra sex worker clients } \\
\hline Regular & 89 & $63(70.8)$ & 1.0 & \multirow[t]{2}{*}{0.001} & 0 & \multirow[t]{2}{*}{$<0.01$} \\
\hline Casual & 114 & $54(47.4)$ & 2.69 (1.49 to 4.83$)$ & & 2.50 (1.34 to 4.65$)$ & \\
\hline
\end{tabular}


did not permit a more elegant approach, such as audio computer-assisted self-interview (ACASI). We believe that the trust built through HSW-based recruitment and a tolerant NGO interview environment might have reduced the clients' reporting bias, but we do not know this for sure. A second limitation of the study was our inability to assess HIV or other STIs in HSW clients. Our collaborating MSM-friendly NGO felt strongly that this should be a second research step, after we had developed the techniques for reaching and recruiting clients. Further studies on HIV prevalence in both clients and HSWs themselves will help assess the bridging role of HSW clients in HIV transmission to the general population.

Our study suggests that, given the rise in HIV in Pakistan since 2003, HIV is likely to spread further among HSWs, their sexual clients, FSWs and family members. Therefore, there is an urgent need for enhancing prevention-intervention programmes in Pakistan that do not omit HSWs and their clients, even as they seek to engage FSWs, and these interventions should be more focused on behaviour change and condom use. This study has also demonstrated that it is feasible to reach one of the hardest-to-reach study populations-HSW clients-by involving an MSM-friendly NGO and the HSWs themselves.

\author{
Author affiliations \\ ${ }^{1}$ Vanderbilt Institute for Global Health, Vanderbilt University, Nashville, \\ Tennessee, USA \\ ${ }^{2}$ Bridge Consultants Foundation, Karachi, Pakistan \\ ${ }^{3}$ Department of Medicine, Vanderbilt University, Nashville, Tennessee, USA \\ ${ }^{4}$ Dow University of Health Sciences, Karachi, Pakistan \\ ${ }^{5}$ Department of Pediatrics, Vanderbilt University, Nashville, Tennessee, USA
}

Acknowledgements We are grateful to M Blevins for her assistance with the data analysis.

Correction notice The "To cite: ..." information and running footer in this article have been updated with the correct volume number (volume 1).

Funding This study was supported, in part, by NIH grant \#D43 TW001035 (Fogarty AIDS International Training and Research Program).

Competing interests None.

Ethics approval Ethics approval was provided by the Institutional Review Board of Vanderbilt University, USA and Bridge Consultants Foundation, Pakistan.

Contributors AuRS is the principal investigator, had full access to all of the data in the study and takes responsibility for the integrity of the data and the accuracy of the data analysis. $\mathrm{H}-\mathrm{ZQ}$ helped in the statistical analysis and development of the manuscript. AA helped in the data-collection process in Karachi, Pakistan and in the development of manuscript. HC helped on ethical issues of the data-collection process and in designing the questioner. SAS contributed to the conceptualisation and design of this study, and the development of manuscript. SHV contributed to the conceptualisation of the study, development and critical revision of the manuscript.

Provenance and peer review Not commissioned; externally peer reviewed.

Data sharing statement No additional data available.

\section{REFERENCES}

1. HIV/AIDS reported cases. http://www.nacp.gov.pk (accessed 10 Mar 2011).

2. HIV/AIDS estimates Pakistan. http://www.unaids.org (accessed 10 Mar 2011).

3. Ministry of Health, National AIDS Control Programme. HIVIAIDS Surveillance Project of Pakistan: Round 3. National AIDS Control Program Pakistan, 2008.

4. Shah SA, Altaf A, Mujeeb SA, et al. An outbreak of HIV infection among injection drug users in a small town in Pakistan: potential for national implications. Int J STD AIDS 2004;15:209.

5. Bokhari A, Nizamani NM, Jackson DJ, et al. HIV risk in Karachi and Lahore, Pakistan: an emerging epidemic in injecting and commercial sex networks. Int J STD AIDS 2007:18:486-92.

6. Khan AA, Khan A. The HIV epidemic in Pakistan. J Pak Med Assoc 2010;60:300-7.

7. Population Council Pakistan, National AIDS Control Programme. Study of Sexual Transmitted Infection Men in General Population. Population Council, 2007.

8. Faisel A, Cleland J. Migrant men: a priority for HIV control in Pakistan? Sex Transm Infect 2006;82:307-10.

9. Mastro TD, Satten GA, Nopkesorn T, et al. Probability of female-tomale transmission of HIV-1 in Thailand. Lancet 1994;343:204-7.

10. Royce RA, Sena A, Cates W, et al. Sexual transmission of HIV. N Engl J Med 1997;336:1072-8.

11. Morris M, Podhisita $C$, Wawer MJ, et al. Bridge populations in the spread of HIV/AIDS in Thailand. AIDS 1996;10:1265-71.

12. Shah NS, Shiraishi RW, Subhachaturas W, et al. Bridging populations - sexual risk behaviors and HIV prevalence in clients and partners of female sex workers, Bangkok, Thailand 2007. J Urban Health 2011;88:533-44.

13. Hawkes S, Collumbien M, Platt L, et al. HIV and other sexually transmitted infections among men, transgenders and women selling sex in two cities in Pakistan: a cross-sectional prevalence survey. Sex Transm Infect 2009;85(Suppl 2):ii8-16.

14. Ministry of Health, Government of Pakistan. HIVIAIDS Surveillance Project of Pakistan: Pilot Round. 2005.

15. National AIDS Control Programme, London School of Hygiene and Tropical Medicine. Sexually Transmitted Infections and HIV among People at High Risk. 2007.

16. Rajabali A, Khan S, Warraich HJ, et al. HIV and homosexuality in Pakistan. Lancet Infect Dis 2008;8:511-15.

17. Emmanuel F, Blanchard J, Zaheer HA, et al; HASP team. The HIV/ AIDS Surveillance Project mapping approach: an innovative approach for mapping and size estimation for groups at a higher risk of HIV in Pakistan. AIDS 2010;24(Suppl 2):S77-84.

18. Day $\mathrm{S}$, Ward $\mathrm{H}$, Ghani A, et al. Sexual histories, partnerships and networks associated with the transmission of gonorrhoea. Int J STD AIDS 1998;9:666-71.

19. Mgalla Z, Pool R. Sexual relationships, condom use and risk perception among female bar workers in north-west Tanzania. AIDS Care 1997;9:407-16. 